Dicle University Journal of Engineering (DUJE)

web: http://dergipark.gov.tr/dumf

Araștırma Makalesi / Research Article

\title{
Tek Katlı Betonarme Bir Yapı Üzerinde Operasyonel Modal Analiz Uygulaması
}

\section{Operational Modal Analysis Application on a Single Storey Reinforced Concrete Building}

\section{Dilek Okuyucu ${ }^{1}$}

${ }^{1}$ Erzurum Teknik Üniversitesi, İnşaat Mühendisliği Bölümü, Erzurum, okuyucu@erzurum.edu.tr

\begin{tabular}{|c|c|}
\hline MAKALE BİLGİLERİ & ÖZET \\
\hline Makale geçmişi: & \multirow{5}{*}{$\begin{array}{l}\text { Tahribatsız yöntemlerle malzemelerin mekanik özelliklerinin belirlenmesi oldukça yaygın uygulaması olan } \\
\text { çalışmalardır. Yapı dinamik davranış parametrelerinin yerinde belirlenmesi amacıyla yapılan çalışmalar da } \\
\text { tahribatsız yöntem uygulamaları içerisinde yer almaktadır. Bu yöntemlerden birisi olan operasyonel modal analiz } \\
\text { uygulaması bu çalışmanın ana unsuru olarak sunulmaktadır. Çalışma kapsamında, statik ve mimari projesi } \\
\text { olmayan tek katlı ve her iki plan doğrultusunda iki açıklıklı bir betonarme yapı ele alınmıştır. Öncelikle yapının } \\
\text { rölevesi çıkarılmış, donatı tespit cihazı ile ana taşıyıı elemanların donatı detayları belirlenmiş, ultrasonik test ve } \\
\text { Schmidt çekici uygulamaları ile beton malzeme özellikleri yerinde tayin edilmiştir. İkinci aşamada yapının } \\
\text { SAP2000 yazılımı kullanılarak yapısal analizde kullanılacak sonlu elemanlar modeli oluşturulmuş ve teorik modal } \\
\text { analizi yapılmıştır. Üçüncü aşamada operasyonel modal analiz çalışmas gerçekleştirilmiştir. Bu kapsamda teorik } \\
\text { modal analiz sonuçları dikkate alınarak; yapı üzerinde ivmeölçer sensör yerleşimi yapılmış ve ortam titreşimi } \\
\text { kayıtları alınmıştır. Toplanan veri Artemis Modal Pro yazılımı kullanılarak işlenmiş ve yapının yerindeki mod } \\
\text { şekilleri ve frekansları elde edilmiştir. Teorik ve deneysel mod şekillerinin uyuştuğu ancak; ilgili frekans } \\
\text { değerlerinin farklı olduğu belirlenmiştir. Sonlu elemanlar modeli üzerinde yapılan kalibrasyon çalışmaları } \\
\text { neticesinde dolgu duvarların modelde ihmal edilmesi halinde deneysel olarak elde edilen modal davranış } \\
\text { parametrelerinin hesaplanmasının mümkün olmadığı sonucuna ulaşılmıştır. }\end{array}$} \\
\hline Geliş: 4 Mayıs 2020 & \\
\hline Düzeltme: 31 Mayss 2020 & \\
\hline Kabul: 31 Mayis 2020 & \\
\hline $\begin{array}{l}\text { Anahtar kelimeler: } \\
\text { Operasyonel modal analiz, } \\
\text { teorik modal analiz, } \\
\text { tahribatsiz muayene, } \\
\text { ultrasonik test, } \\
\text { yapisal model kalibrasyonu }\end{array}$ & \\
\hline
\end{tabular}

Doi: $10.24012 /$ dumf. 731668

\begin{tabular}{|c|c|}
\hline ARTICLE INFO & ABSTRACT \\
\hline Article history: & \multirow{6}{*}{$\begin{array}{l}\text { Determination of the mechanical properties of materials by non-destructive methods is quite common practice. } \\
\text { The studies conducted in the field of determining the dynamic behavior parameters of the structures are also } \\
\text { included in non-destructive methods. Operational modal analysis, a non-destructive method, is presented as main } \\
\text { element of this study. A single storey reinforced concrete structure with the lack of static and architectural projects } \\
\text { was studied. First of all, the structure was relieved, reinforcement details of load bearing elements were determined } \\
\text { by reinforcement detection device, and the properties of the concrete material were determined in-situ by } \\
\text { ultrasonic testing and Schmidt hammer applications. Secondly, finite element model was created by using } \\
\text { SAP2000 software and theoretical modal analysis was performed. In the third stage, operational modal analysis } \\
\text { was performed. Considering the results of theoretical modal analysis; accelerometer sensor instrumentation was } \\
\text { made and ambient vibration recordings were taken. The collected data was processed by using Artemis Modal Pro } \\
\text { software and in-situ mode shapes and frequencies were obtained. The theoretical and experimental mode shapes } \\
\text { were defined to be similar; whereas the related frequency values were obtained to be different. As a result of the } \\
\text { calibration studies on the finite element model, it was concluded that it was not possible to calculate the } \\
\text { experimentally obtained modal behavior parameters if the fill walls were omitted in the finite element model. }\end{array}$} \\
\hline Received: 4 May 2020 & \\
\hline Revised: 31 May 2020 & \\
\hline Accepted: 31 May 2020 & \\
\hline Keywords: & \\
\hline $\begin{array}{l}\text { Operational modal analysis, } \\
\text { theoretical modal analysis, } \\
\text { nondestructive testing, } \\
\text { ultrasound testing, } \\
\text { structural model calibration }\end{array}$ & \\
\hline
\end{tabular}

* Sorumlu yazar / Correspondence

Dilek OKUYUCU

$\bowtie$ okuyucu@erzurum.edu.tr 


\section{Giriș}

Mevcut betonarme yapıların durum tespiti ve performans analizi çalışmalarında tahribatsız muayene yöntemleri yaygın olarak kullanılmaktadır. Tahribatsız yöntemlerle beton malzeme mekanik özelliklerinin tespitinin yanı sıra; betonarme donatı detaylarının tayini de mümkündür. Silsilenin devamında; tahribatsız yöntemlerle yapıların dinamik davranış parametrelerinin yerinde tespiti, hatta yapisal hasar durumunun tayini de mümkün hale gelmiştir. Detayları takip eden bölümlerde sunulacak olan bu çalışma; hakkında hiçbir teknik bilgi (proje, çizim, hesaplama, vb.) bulunmayan tek katlı bir betonarme yapı üzerinde tamamen tahribatsız yöntemlerle gerçekleştirilmiş bir modal davranış inceleme çalışması hakkında bilgi sunmaktadir.

Çalışma kapsamında gerçekleştirilen tahribatsız yöntem kullanımına ilişkin ilk uygulama, incelenen yapıda kullanılan beton malzeme karakterizasyonu amacıyla yapılmıştır. Beton malzeme basınç dayanımının tahribatsız yöntemlerle belirlenmesi söz konusu olduğunda, kuşkusuz, akla gelen ilk yöntem Schmidt çekici uygulamasıdır ki; bu çalışmada da kullanılan ilk yöntem olmuştur. Bu metotta kullanılan Schmidt çekici 1948 yılında geliştirilmiş olup, URL-1 [1]' de ifade edildiği şekilde, uygulama kolaylığ nedeniyle tüm dünyada yaygın bir şekilde kullanıldığı bilinmektedir. $\mathrm{Bu}$ yöntemde sertleştirilmiş çelikten yapılmış çekicin beton yüzeyinde yaptığı darbe sonucunda oluşan geri sıçrama miktarı ölçülmekte ve teorik bir bağıntı olmamakla birlikte beton dayanımı ile geri sıçratma miktarı arasında ampirik bağıntılar kullanılarak beton basınç dayanımının tayini/tahmini yoluna gidilmektedir. Ulusal ve uluslararası literatürde Schmidt çekici yönteminin muhtelif uygulamalarına ilişkin sayısız çalışma bulunmakta; son yıllarda yöntemin farklı türde beton malzemeler üzerindeki başarısının araştırıldı ̆̆ çalışmalara doğru yönelme olduğu görülmektedir. Kazemi vd. [2] çalışmalarında geri dönüşüm agregası kullanılarak imal edilen beton dayanımının tayininde Schmidt çekici yönteminin etkinliğini araştırırken; Müller vd. [3] çalışmalarında polipropilen lifle üretilmiş ve yüksek sicaklığa maruz bırakılmış beton dayanımının Schmidt çekici uygulaması ile tayinini incelemişlerdir.

Çalışmanın beton malzeme karakterizasyonu aşamasında kullanılan bir başka tahribatsız ama tartışmalı metot ise ultrases yöntemidir. Tekniğin temel yaklaşımı, beton malzeme içerisine gönderilen ses dalgalarının beton içerisinde yayılma hızı kullanılarak beton dayanımı, elastik modül, boşluk oranı, çatlak durumu, vb. parametrelerinin kestirimlerinin yapılmasıdır. Beton ortamı içerisinde yayılan ses dalgalarının yayılma hizı ile incelenen parametre arasında uygun korelasyon bağıntılarının kullanılması esastır. Ancak, ultrases dalgası yayılma hızı ile beton basınç dayanımı arasındaki ilişkinin ifade edildiği tek bir korelasyon olduğunu söylemek mümkün değildir. Bu hasarsız yöntem, çok sayıda nokta üzerinden okuma yapılabilmesi, zamandan tasarruf sağlanması ve taşıyıcı elemanlara zarar vermemesi açısından tercih edilmektedir. Yöntem kullanılarak gerçekleştirilen çok sayıda bilimsel çalıșma bulunmakla birlikte; beton basınç dayanımının ultrases yöntemi ile tayini amacıyla gerçekleştirilen Whitehurst [4] çalışmasının bu alandaki ilk çalışmalardan birisi olduğunu ifade etmek mümkündür. Durmuş ve Y1lmaz [5] ultrases yönteminin farklı bir parametre tayininde kullanımına örnek olarak sundukları çalışmalarında yapay puzolan katkılı betonlarda su emme derinliğinin tayini için utrases yöntemini kullanımına ilişkin araştırma sonuçlarına yer verirken; Abdullah vd. [6] çalışmalarında beton elastik modülünün ultrases yöntemi ile tahmini alanında gerçekleştirdikleri deneysel çalışmalarını literatüre geçirmişlerdir. Ahn vd. [7] araştırması ise beton içerisindeki mikro çatlak dağılımının belirlenmesinde ultrases yöntemi kullanımının olumlu sonuçlar verdiğini raporlayan bir çalışmadır.

Tahribatsız yöntem kullanılarak gerçekleştirilen bir başka uygulama ise mevcut betonarme yapı taşıyıc1 elemanlarında donatı tespitinin yapılmasıdır. Ultrases yöntemini esas alarak imal edilen betonarme donatı konumlandırıcıları, betonarme yapılarda çelik donatı çubuklarının konumunu bulmak ve beton kaplama boyutlarını ölçmek için kullanılmaktadır. Bununla birlikte; cam elyaf içerikli donatı, ardgerme ve öngerme halatları gibi özel donatıların doğru bir şekilde 
tayini için ultrasonic sistemlerin kullanılamayacağı, bu çalışmalarda zemine nüfuz eden radar esaslı sistemlerin kullanılması gerektiği URL-2 [8] kaynağında ifade edilmektedir. Yöntem, mevcut betonarme yapıların durum tespiti çalışmalarında sıklıkla kullanılmakla birlikte; bilimsel literatürde konuya ilişkin çok sayıda çalışmaya ulaşmak mümkündür. Rathod vd. [9] çalışmalarında Kanada' da 1950 ve sonrasındaki 30 yıllık süre içerisinde inşa edilmiş çoğunluğu köprü türü olan yapılara ait betonarme döşemelerde donatı tayininde radar ve ultrases esaslı cihaz kullanımlarını karşılaştırmaları açısından dikkat çekici bir çalışma olarak değerlendirilmektedir.

Gelişen teknolojinin inşaat mühendisliği araştırmacılarına sunduğu teknik imkânlar; tahribatsız yöntemlerle mevcut yapılar için dinamik kimliklendirme çalışmaları yapılmasının önünü açtığı Brickner ve Ventura [10] kaynağında ifade edilmektedir. Burada esas olanın, yapıdan alınan titreşim kayıtları kullanılarak mod şekli, frekans ve sönüm oranı gibi modal davranış parametrelerinin deneysel olarak belirlenmesi olduğu Yetkin [11] çalışmasında da belirtilmektedir. Elde edilen veri, yapısal analize esas model doğrulama (Link [12]), yapım kalitesi kontrolü (Altunışık vd. [13]), hasar tespiti (Polimeno vd. [14]), dinamik kimliklendirme (Şafak ve Çelebi [15]) vb. çalışmalarda değerlendirilebilmektedir.

Tüm yapılar gündelik aktivitelerin getirdiği titreşim ve çevresel etkiler nedeni ile sürekli olarak titreşirler. Bunlar insanların algılayamadığı, ancak hassas sensörlerin algılayabildiği tip titreşimlerdir. Bu titreşimlerin ölçüm hassasiyeti yüksek sensörlerle uygun bir yerleşim planı dâhilinde ve yeteri kadar uzun bir süre boyunca kaydedilmesi sonucunda elde edilen veri kullanılarak, tüm yapının dinamik yükler altında karakteristik özelliklerini $(\bmod$ şekilleri, frekans, salınım periyodu, sönüm vb.) belirleyen sonuçlar elde edilebileceği Zhu vd. [16] çalışmasında ifade edilmektedir. Yapıların bu şekilde dinamik davranış parametrelerinin belirlenmesi amacıyla yapılan çalışmalar pek çok kaynakta olduğu gibi, Cantieni [17] tarafından da deneysel modal analiz olarak adlandırılmaktadir. $\mathrm{Bu}$ yöntemin esası, yapıya uygulanan bir etki altında yapının göstermiş olduğu tepkilerin ölçülmesine dayanmaktadır. Ölçülen etki ve tepki sinyalleri arasında tanımlanan fonksiyon her bir yapı için karakteristik özellikte olan dinamik davranış parametrelerini içermektedir. Bayraktar vd. [18] çalışmasında, bu yöntemin makine parçalarının titreşim analizleri, uçaklardaki titreşim problemlerinin belirlenmesi, yap1 dinamik karakteristiklerinin belirlenmesi gibi birçok mühendislik alanında yaygın olarak kullanıldığı ifade edilmektedir.

Bir deneysel modal analiz metodu olan operasyonel modal analiz yönteminde, çevresel etkilerin yapıda oluşturduğu titreşimler ölçülür. Yapıların tepki ölçümlerinde herhangi bir titreştirici kullanılmaz. Bu yöntem, çevresel titreşim testi olarak da adlandırılır. Uygulamada, yapı için teorik modal analiz sonuçları esas alınarak belirlenen noktalardan ivme ölçümleri alınır ve muhtelif veri analiz yöntemleri kullanılarak yapı dinamik parametreleri elde edilir. Brickner vd. [19] çalıșması ortam titreşimlerine yapı tarafından gösterilen tepkilerin frekans alanında çözümleme yöntemiyle irdelendiği araştırmalara örnektir.

$\mathrm{Bu}$ çalışma, yukarıda değinilen tahribatsız yöntemlerle betonarme malzeme karakterizasyonu ve mevcut betonarme bir yapının dinamik davranış parametrelerinin belirlenmesine bir örnektir. Bu amaçla, mimari ve statik projesi olmayan tek katlı bir betonarme yap1 ele alınmış; öncelikle rölevesi çıkarılmış, beton malzeme dayanımı tayini için Schmidt çekici ve ultrases yöntemleri uygulanmış, taşıyıcı elemanlarda donatı tespiti yapılmış ve saha çalışmasının son aşamasında yapı tek eksenli ivmeölçerler ile donatılarak titreşim kayıtları alınmıştır. İvme kayıtları analiz edilerek mod şekli, modal frekans ve sönüm oranları hesaplanmış ve yapısal analize esas model üzerinde elde edilen teorik modal analiz sonuçları ile karşılaştırılmıştır. Çalışma neticesinde, yapının sonlu elemanlar modeli üzerinde deneysel modal analiz sonuçlarına yakın sonuçlar hesaplanabilmesi için model kalibrasyonu yapılması gerekmiş ve bu amaçla dolgu duvar etkilerinin yansitıldığ 1 yeni bir model oluşturulmuştur. 


\section{Materyal ve yöntem}

Çalışmanın amacına uygun olacak şekilde bir yapının incelenmesi gerektiğinden hareketle yapılan araştırmada; bir kamu kurumuna ait piknik alanı idari binası olarak kullanılan yapıya ulaşılmış ve çalışmanın öznesi olarak bu yapı seçilmiştir. Bu bölümde, incelenen yapı ve takip edilen yöntem hakkında detaylı bilgi sunulmaktadir.

\section{İncelenen yapı hakkında bilgi}

Araştırmaya konu olan tek katlı betonarme yapıya ait statik ve mimari projelere erişim mümkün olmamıştır. $\mathrm{Bu}$ nedenle yapının rölevesi alınmış ve taşıyıcı sistemi yerinde inceleme sonucunda belirlenmiştir. Yap1 $7.85 \times 7.50 \mathrm{~m}$ plan ölçülerine sahip olup kat yüksekliği $3 \mathrm{~m}$ olarak ölçülmüştür. Yapı, her iki plan doğrultusunda iki açıklıklı betonarme çerçeve sistem olarak inşa edilmiş ve çerçeve açıklıklarında boşluklu tuğla dolgu duvarlar kullanılmıştır. Yap1 ön cephe görünümü Şekil 1' de; mimari ve taşıyıcı sisteme ait çizimler ise Şekil 2' de sunulmaktadır.

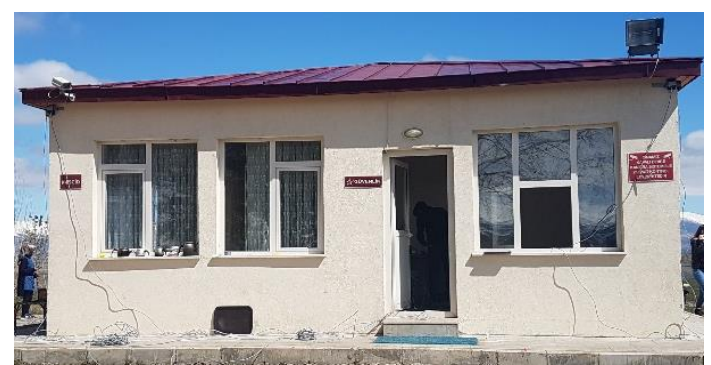

Şekil 1. Yapı ön cephe görünümü

Figure 1. Front side view of the building
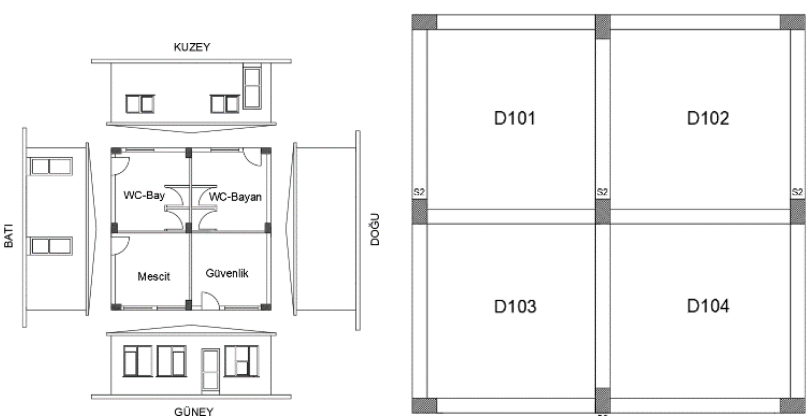

Şekil 2. Yapıya ait plan çizimleri

Figure 2. Plan drawings of the building

\section{Yöntem}

Çalışmanın başlangıcında yetkili idareden yasal izinler alınmış, sonrasında saha çalışması aşamasına geçilmiştir. Bu kapsamda takip edilen yöntemi aşağıdaki sıralama ile sunmak mümkündür.

1. Yapının yerinde incelenmesi ve fotoğraflanması

2. Yapının rölevesinin çıkarılması (mimari çizimler ve taşıyıcı sistem planı)

3. Schmidt çekici ve ultrases yöntemleri ile beton malzeme dayanımının tayini

4. Donatı tespit cihazı ile donatı detaylarının çıkarılması

5. Dolgu duvarlar olmaksızın, yap1 sonlu elemanlar modelinin oluşturulması ve teorik modal analiz yapılması

6. Teorik modal analiz sonuçlarına göre ivmeölçer sensör yerleşim planlarının çıkarılması

7. Yap1 üzerinde ivmeölçer sensör yerleşimlerinin yapılması ve ortam titreşimi kayitlarının alınması

8. Ortam titreşim kayıtları kullanılarak yapılan analizlerle yapının modal davranış parametrelerinin elde edilmesi

9. Teorik ve deneysel modal analiz sonuçlarının karşılaştırılması

10. Teorik modal analiz sonucunda deneysel modal analiz sonuçlarının elde edilmesine imkân sağlayacak şekilde sonlu elemanlar modelinin güncellenmesi

Çalışmanın ilk beş aşaması, inşaat mühendisliği saha uygulamalarında sıklıkla tatbik edilen yöntemleri kapsamaktadır. Röleve alınırken öncelikle yapının plandaki toplam oturma alanı boyutları ve kat yüksekliği ölçülmüş ve sonrasında açıklılar belirlenmiştir. Ölçümlerde hassas lazer metre ve yer yer çelik şerit metre kullanılmıştır. Mimari çizimler AUTOCAD [20] yazılımı kullanılarak hazırlanmıştır.

Beton malzeme dayanımının tayininde Schmidt darbe çekici ve ultrases yöntemi uygulamaları birlikte yapılmıştır. İncelenen bina taşıyıcı elemanları üzerindeki sıvanın kaldırılması ve uygulamanın doğrudan beton yüzey üzerinden yapılması mümkün olmamıștır. Ancak, bir tür 
sağlama olması açısından incelenen binanın hemen bitişiğinde bulunan ve yapı ile aynı zamanda yapıldığı bilinen su deposu yapısındaki sıvasız yüzeylerde de ölçümler alınarak karşılaştırmalı olarak değerlendirmeler yapılmıştır. Beton malzeme üzerinde yapılan çalışma sonrasında; taşıyıcı elemanlarda çelik donatı tespiti için uygulama yapılmış ve tüm taşı1c1 elemanlar (kiriş, kolon ve döşeme) taranmıştır. Bahsi geçen tüm uygulamalarda Proceq marka cihazlar kullanılmıştır. Uygulamalara ilişkin görseller Şekil 3' te sunulmaktadir.
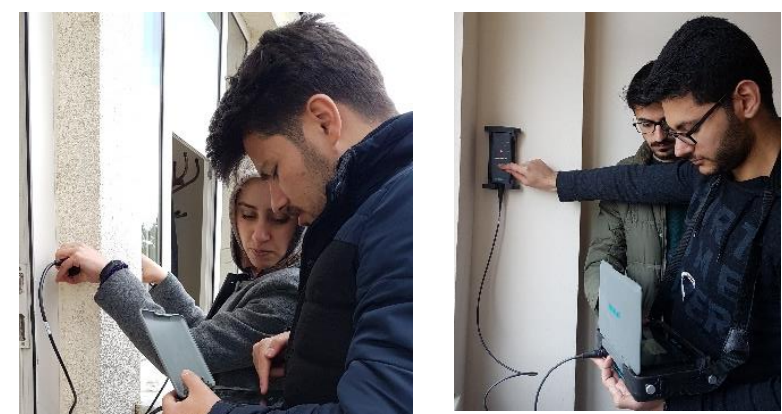

Şekil 3. Saha çalışmasından görüntüler

Figure 3. Views from site studies

Yapının malzeme ve kesit özellikleri tayin edildikten sonra; operasyonel modal analiz çalışması öncesi sonlu elemanlar modelinin oluşturulması ve teorik modal analiz yapılarak dinamik davranış parametrelerinin, mod şekilleri ve modal frekanslar, hesaplanması önemli bir aşamadır. Zira, bu model üzerinde elde edilecek analiz sonuçları hem titreşim kayıtları için sensör yerleşim planının belirlenmesinde kullanılmakta hem de teorik ve deneysel modal davranış parametrelerinin karşılaştırmalı olarak incelenmesine esas teşkil etmektedir.

Yerinde inceleme çalışmaları sonucunda elde edilen kolon, kiriş, döşeme ve duvar özellikleri dikkate alınarak; yapı bilgisayar ortamında SAP2000 [21] yazilımı kullanılarak modellenmiştir. $\mathrm{Bu}$ modelde dolgu duvarların yapısal davranışa olan katkısı ihmal edilmiş; sadece ağırlıkları dikkate alınmıştır. Çatı ölü yükü $0.4 \mathrm{kN} / \mathrm{m}^{2}$ olarak döşemelere tanıtılmış ve duvar yüklerinin de dâhil edilmesi için modeldeki ölü yük faktörü \%30 arttırılarak analize esas sonlu elemanlar modeli oluşturulmuştur. Yapısal modele ait genel bir görüntü Şekil 4' te sunulmaktadır.

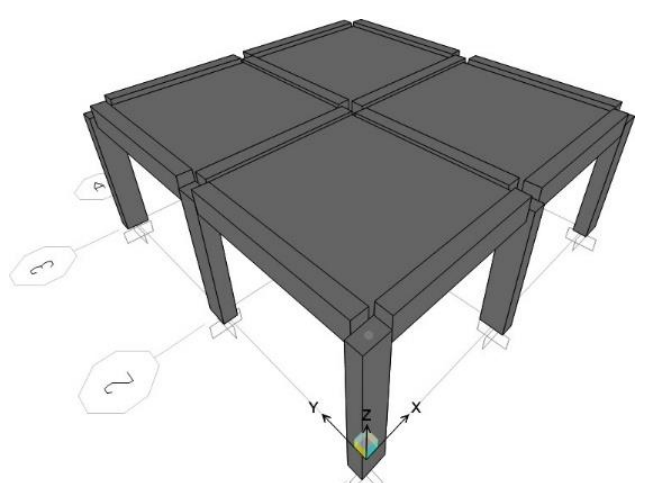

Şekil 4. Yapının sonlu elemanlar modeli Figure 4. Finite element model of the building

Yapısal analize esas model oluşturulup, teorik modal analiz yapıldiktan sonra operasyonel modal analiz çalışması aşamasına geçilmiştir. $\mathrm{Bu}$ aşamada yapılan çalışmaların nispeten daha detaylı olarak sunulmasinda yarar görüldügünden; bu bölümü takip eden kısımda detaylandırılmaktadır.

\section{Operasyonel modal analiz uygulaması}

Operasyonel modal analiz, mevcut yapıların dinamik davranış parametrelerinin yerinde tayini amaciyla kullanılan tahribatsız deneysel bir yöntemdir. Farklı mühendislik alanlarında uygulama bulan operasyonel modal analiz, inşaat mühendisliği alanında tarihi yığma yapılardan (Saisi vd. [22], Özkul [23], Kocaman vd. [24], Aslay ve Okuyucu [25]) çelik yapılara (Türker [26], Kömür vd. [27]) kadar farklı taşıyıcı sisteme sahip yapilarda muhtelif amaçlarla uygulanmaktadır. Yöntem, bu çalışmada tek katlı betonarme çerçeve türü taşıyıcı sistemi olan bir yapıya uygulanmış ve aşağıda sıralanan aşamalar takip edilmiştir.

\section{İvmeölçer sensörlerin yerleştirilmesi ve titreşim kayıt sisteminin kurulmast}

Operasyonel modal analiz uygulamasının birinci aşaması ivmeölçer sensör yerleșimi çalışmasından oluşmaktadır. Çalışmada toplam 8 adet tek eksenli ölçüm alan, kablolu ivmeölçer sensör kullanılmıştır. Sensörler Şekil 5' te sunulan krokiye uygun olarak bina köşelerindeki kolonların üst uçlarına yerleştirilmiştir. Yapının teorik modal analizinde hesaplanan ilk $3 \mathrm{mod}$ şeklinde; binanın düşey hareketine ilişkin bir mod şekli olmadığı dikkate alınarak, düşey 
yönde titreşim kaydı alınmamıştır. İvmeölçer sensörler sıcak silikon kullanılarak ölçüm noktalarına sabitlenmiş ve sonrasında kablolama işlemi yapılmıştır.
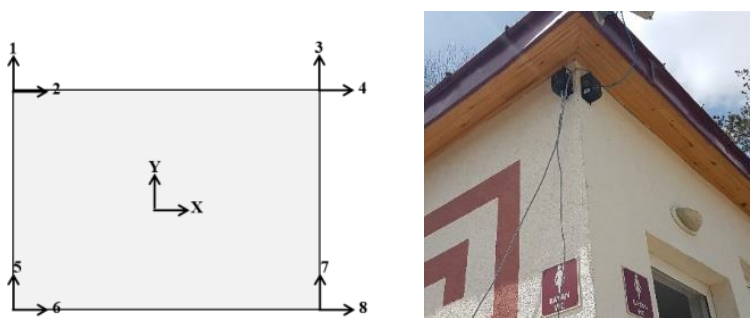

Şekil 5. İvmeölçer sensör yerleşim planı ve sensör yerleştirme uygulaması

Figure 5. Accelerometer instrumentation plan and view of application

Veri toplama işlemi 16 kanallı, taşınabilir dinamik veri toplama sistemi kullanılarak yapılmıştır. Veri kayıt işlemleri için TestLab Network [28] isimli yazılım kullanılmıştır. Veri toplama ve kayıt alma sisteminin genel bir görüntüsü Şekil 6' da sunulmaktadır.

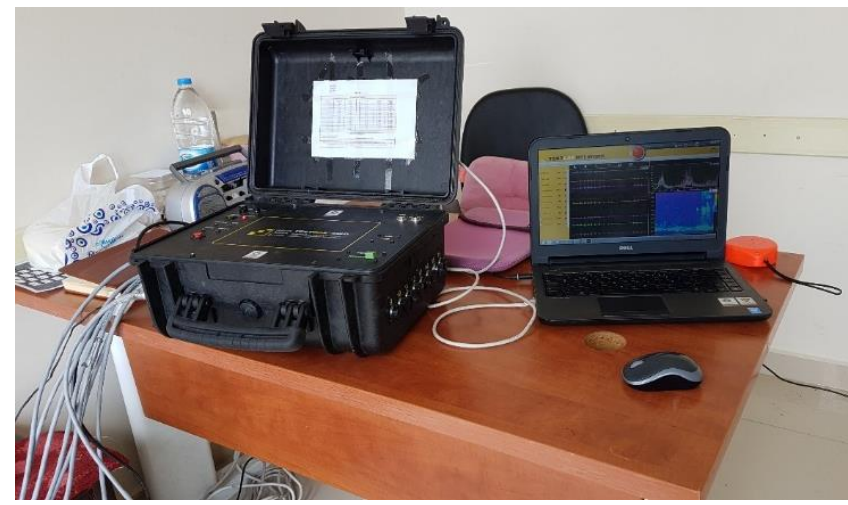

Şekil 6. Veri toplama sistemi genel görüntüsü

Figure 6. General view of data acquisition system

\section{Titreșim (ivme) kayıtlarının alınmast}

Sensör yerleşimi tamamlandıktan sonra, öncelikle birkaç kez pilot ölçüm alınmış, bazı sensörler için kablo değişimi gerekli görülmüştür. Sistemde gerekli tüm kontroller yapıldıktan sonra titreşim kaydı aşamasına geçilmiştir.

Operasyonel modal analiz çalışmasında, yapının rastgele ortam titreşimlerine verdiği tepkilerin ölçülmesi ve bu verinin işlenmesi suretiyle modal davranış parametrelerinin elde edilmesi esastır. $\mathrm{Bu}$ nedenle, yap1 tepkisinden (ölçülen ivme kayıtları) modal davranış parametrelerinin elde edilebileceği bir titreşim kaydının alınması son derece önemlidir. Çalışma yapılan binanın bulunduğu bölgede yapının tepki verdiği temel titreşim kaynakları; yapıya yaklaşık $50 \mathrm{~m}$ mesafede bulunan ana yoldan geçen motorlu araç kaynaklı zemin titreşimleridir. Ayrıca, çalışma yapılan gün piknik alanında çevre temizliği çalışmasının yapıldığı bir güne tesadüf etmiştir. Bu amaçla, yapı çevresinde sıklıkla römork bağlı traktörler hareket halinde olmuştur. Bu hususlar dikkate alınarak, ölçümler taşıt trafiğginin oldukça yoğun olduğu 11:00 - 14:00 saatleri arasında alınmıştır.

Titreşim kayıt süresi; yapıyı titreştiren sinyalin spektral şekli ve süresi, harmonik titreşimlerin varlığı, deneye tabi tutulan yapının karmaşıklığı, ölçüm ekipmanlarının kalitesi, vb. pek çok parametreye bağlıdır. Ancak, kabaca bir yaklaşımla dikkate alınan en düşük mod şekline ait periyot değerinin 500 katından daha fazla süre ile ölçüm alınması pratikte önerilmektedir. Buna ek olarak, ölçülen tepkilerde baskın harmonik titreşimlerin bulunması durumunda kayıt süresinin daha da uzun tutulması gerektiği; Jakobsen ve Andersen [29] çalışmasında ifade edilmektedir.

Tüm bu hususlar dikkate alınarak; 6 set 10 dakika ve 2 set 20 dakika süreli olmak üzere toplam 8 set ivme ölçüm ve kayıt işlemi gerçekleştirilmiştir. İvme ölçüm ve kayıt frekansı $200 \mathrm{~Hz}\left(\Delta_{t}=0.005 \text { saniye }\right)^{\prime}$ dir. Ölçüm birimi "g" dir.

\section{Ivme kayıtları kullantlarak mod şekilleri ve frekanslarının elde edilmesi}

Yapının ortam titreşimlerine verdiği tepkiler ivme kayıtları olarak ölçülmüş ve Artemis Modal Pro [30] isimli yazılım kullanılarak işlenmiştir. $\mathrm{Bu}$ kapsamdaki çalışma beş aşamada gerçekleştirilmiştir

1. Model geometrisinin oluşturulmast: Yap1 geometrisine uygun olarak analize esas model oluşturmuş ve model toplam 8 dügüm noktasından teşkil edilmiştir. Ana taşıyıcı 
olmaması nedeniyle çatı geometrisi modele yansitılmamıştır.

2. Ivme kayıt dosyalarının yazllıma tanıtılması: İvme kayıtlarının yer aldığı veri dosyaları Artemis Modal Pro yazılımına tanıtılmış; ölçüm aralığı, ölçüm birimi gibi parametreler dikkatle işlenmiş ve gerekli kontroller yapilmıştır.

3. Titreşim kayıtlarının modele uygulanması ve analize hazır hale getirilmesi: Yapisal titreşim kaydı alınan noktalarda ölçüm yönüne sadık kalınmak kaydıyla; titreşim kayıtları modele tanıtılmıştır. Kaydedilen toplam 8 set veri için bu işlem ayrı ayrı yapılmış ve her bir ölçüm ile model ayrı ayrı analiz edilecek şekilde çalışma gerçekleştirilmiştir.

4. Analiz yapılarak mod şekilleri ve modal frekansların elde edilmesi: $\mathrm{Bu}$ aşamada veri tanıtımı yapılmış nihai model üzerinde analiz çalışması yapılarak modal davranış parametreleri elde edilmeye çalışılmıştır. Yapının teorik frekans değerleri dikkate alınarak; $0-20 \mathrm{~Hz}$ aralığında spektral yoğunluk fonksiyonları hesaplanmıştır. Öncelikle Frekans Alanında Çözümleme (Frequency Domain Decomposition - FDD) tekniği kullanılarak, otomatik olarak mod şekli belirleme çalışması yapılmıştır. $\mathrm{Bu}$ çalışmada saat 12:50:48 itibariyle alınan 10 dakikalık ölçümle yapılan analizde ilk iki mod şeklinin doğrudan belirlenmesi mümkün olmuştur. Bunun üzerine manuel olarak yapılan çalışma neticesinde üçüncü mod şekli ve ilgili frekans değerleri belirlenmiştir. FDD tekniği ile yapılan analiz çalışmasında sönüm değerlerinin elde edilmesi söz konusu değildir. $\mathrm{Bu}$ nedenle, ikinci yöntem olan Geliştirilmiş Frekans Alanında Çözümleme (Enhanced Frequency Domain Decomposition - EFDD) tekniği kullanılarak ikinci bir analiz yapılmış ve sönüm oranları da hesaplanmıştır.

5. Elde edilen mod şekillerinin tutarlılıklarının irdelenmesi: Deneysel veri işlendikten sonra elde edilen mod şekillerinin güvenilirliğinin genel kabul gören bir yöntemle irdelenmesi önemli bir çalışmadır. Bu amaçla, Modal Güvence Kriteri (Modal Assurance Crtierion - MAC) parametresi kullanılmıştır. Modal güvence kriteri, mod şekillerinin birbirinden bağımsız olup olmadıklarının tayini amacıyla kullanılan bir istatistiki gösterge olduğu Pastor vd. [31] çalışmasında belirtilmektedir. Kriter, sayısal olarak 0 ile 1 arasında değerler almaktadır. 1 değeri tam tutarlı mod şeklini ifade ederken; 0' a yakın değerler modların ayrık olduğu URL-3 [32] kaynağında ifade edilmektedir.

Teorik ve deneysel modal analiz sonuçları karşılaştırıldığında ilk 3 mod şeklinin aynı; ancak ilgili modal frekansların farklılık gösterdiği belirlenmiştir. $\mathrm{Bu}$ değerlendirme neticesinde, yapısal analize esas sonlu elemanları modelinin deneysel modal analiz sonuçlarını verecek şekilde güncellenmesi amacıyla çalışma yapılmıştır. $\mathrm{Bu}$ aşamada öncelikle beton malzeme elastik modülünün değiştirilmesi yöntemi kullanılmış; ancak tutarlı sonuçlar elde edilememiştir. Devamında, dolgu duvarların çapraz elemanlar olarak modele eklenmesi yoluna gidilmiş ve bu aşamada duvar boşluk oranları dikkate alınarak her bir çapraz eleman için ayrı ayrı elastik modül değeri hesaplanmıştır.

\section{Bulgular ve tartışma}

\section{Beton dayanımı tayini ve kesit donatı detaylarının elde edilmesi}

Schmidt beton darbe çekici uygulaması neticesinde beton küp numune dayanımının $\sim 25$ MPa mertebesinde olduğu ve bunun da C20 sinıfi betona tekabül ettiği sonucuna ulaşılmıştır. Bununla birlikte, defaten ölçüm alınmasına ve farklı korelasyon ilişkileri kullanılmış olmasına rağmen ultrases yöntemi ile beton dayanımı tayini yapılması mümkün olmamıştır. Kullanılan cihaza otomatik olarak tanımlanmış kalibrasyon bağıntılarının yanı sıra; Zebari vd. [33] çalışmasında sunulan kalibrasyon bağıntıları da hesaplamalarda kullanılmıştır. Çalışma yapılan kolon ve kiriş yüzeylerinde sıva kaplamalarının olması, çelik donatıların beton içerisinde ilerleyen ultrasonik dalga hız ölçümlerini etkilemesi nedeniyle stabil ölçümler alınamadığı değerlendirilmektedir.

Donatı tespit çalışmaları sonucunda kolonlarda Ø14, kirişlerde ve döşemede ise $\varnothing 12$ boyuna donatı kullanıldığı belirlenmiştir. Tüm 
elemanlarda paspayının ortalama $50 \mathrm{~mm}$ mertebesinde olduğunu söylemek mümkündür. Enine donatı olarak $\varnothing 8 / 150 \mathrm{~mm}$ uygulamasının tüm kolon ve kirişlerde aynı șekilde tatbik edilmiş olduğu belirlenmiştir. Kolon ve kiriş uç bölgelerinde etriye sıklaştırması uygulaması yapıldığı ve burada etriye aralıklarının $\sim 100 \mathrm{~mm}$ olduğu tespit edilmiştir. Kolon ve kirişlere ait kesit detay çizimleri Şekil 7' de sunulmaktadır.
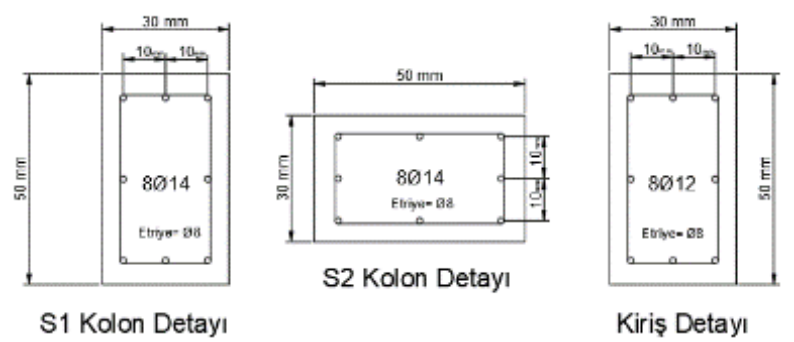

Şekil 7. Taşıyıcı eleman kesit detayları

Figure 7. Sectional details of structural elements

\section{Teorik ve deneysel modal analiz sonuçları}

Operasyonel modal analiz çalışması dâhilinde FDD ve EFDD yöntemleri kullanılarak analizler yapılmış; elde edilen yap1 dinamik davranış karakteristikleri Tablo 1' de sunulmuştur. EFDD yöntemi ile yapılan analiz sonucunda sönüm oranlarının hesaplanması da mümkün olmuştur. Her iki yöntemde de mod şekillerinin aynı olduğu ve hesaplanan modal frekans değerleri arasındaki farkın \%1' den az olduğu belirlenmiştir.

Tablo 1. Operasyonel modal analiz sonuçları

Table 1. Results of operational modal analysis

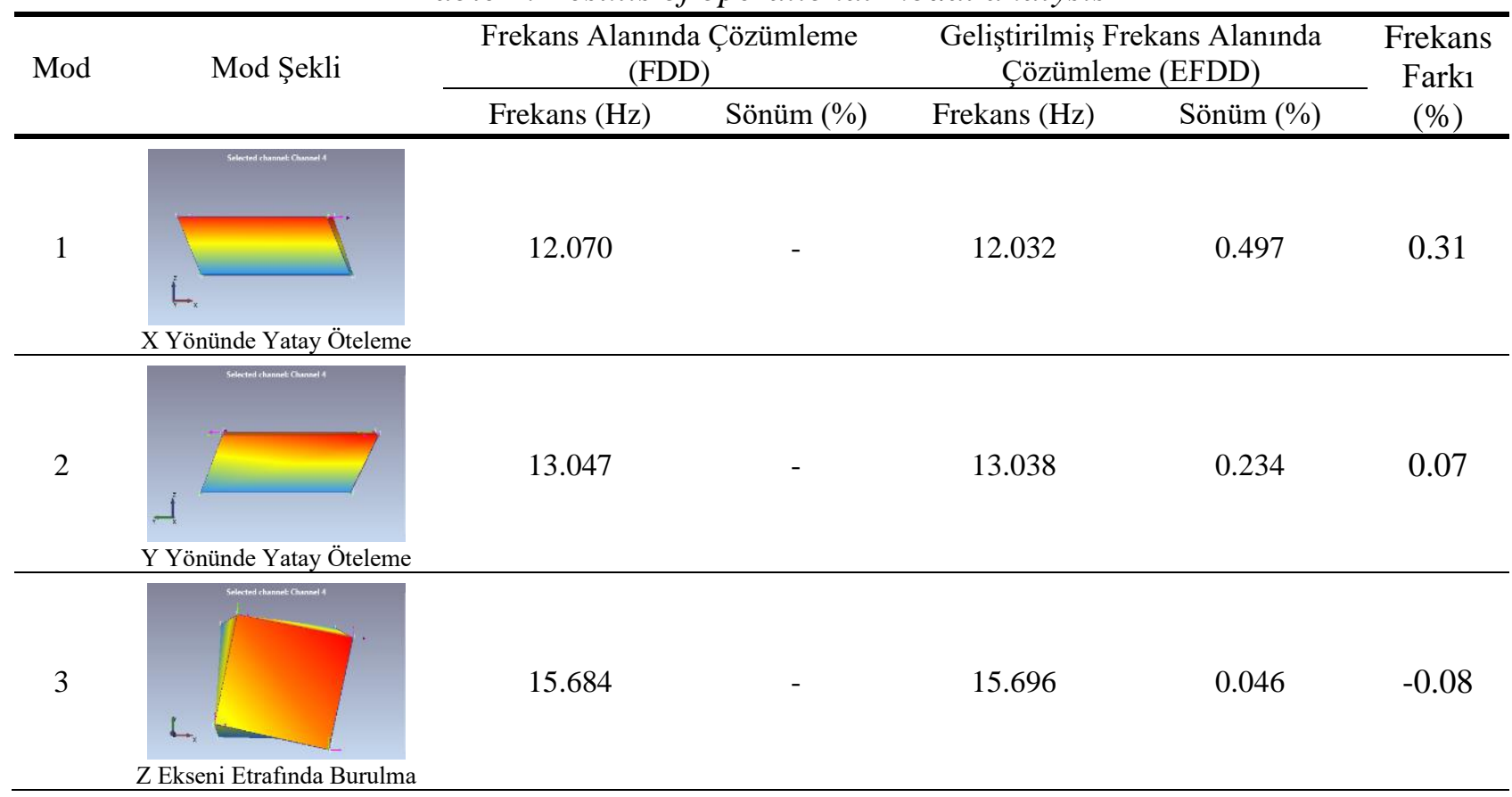

Analizler sonucunda elde edilen mod şekillerinin tutarlı ve ayrık olup olmadıklarının kontrolü amaciyla, Artemis Modal Pro yazılımının hesaplama aracı kullanılarak modal güvenlik kriteri değerleri hesaplanmış ve Tablo 2' de sunulmuştur. Mod şekillerine ilişkin modal güvence kriteri değerleri incelendiğinde, diyagonal sırada yer alan değerlerin tam olarak 1, köşe değerlerin ise sıfıra son derece yakın değerleri olduğu görülmektedir. Bu sonuçlar, operasyonel modal analiz neticesinde elde edilen mod şekillerinin tutarlı ve birbirinden bağımsız 
(ayrık) olduğunu göstermektedir. Bu nedenle; deneysel olarak elde edilen mod şekilleri ve frekansların teorik model kalibrasyonunda kullanılabilecek güvenilirlikte olduğu sonucuna ulaşılmıştır. Teorik ve deneysel modal frekans karşılaştırma ve sonlu elemanlar modeli kalibrasyon çalışmalarında EFDD analizi sonucunda elde edilen deneysel değerlerin kullanılması uygun bulunmuştur.

Tablo 2. FDD ve EFDD analizleri sonucunda elde edilen mod şekillerine ilişkin modal güvence kriteri değerleri

Table 2. Modal assurance criteria values calculated for FDD and EFDD analysis

\begin{tabular}{|c|c|c|c|c|}
\hline \multirow{4}{*}{$\begin{array}{l}\text { Frekans Alanında } \\
\text { Çözümleme (FDD) }\end{array}$} & & $12.07 \mathrm{~Hz}$ & $13.05 \mathrm{~Hz}$ & $15.68 \mathrm{~Hz}$ \\
\hline & $12.07 \mathrm{~Hz}$ & 1 & 0.04383 & 0.09042 \\
\hline & $13.05 \mathrm{~Hz}$ & 0.04383 & 1 & 0.04446 \\
\hline & $15.68 \mathrm{~Hz}$ & 0.09042 & 0.04446 & 1 \\
\hline \multirow{4}{*}{$\begin{array}{l}\text { Geliştirilmiş Frekans } \\
\text { Alanında Çözümleme } \\
\text { (EFDD) }\end{array}$} & & $12.03 \mathrm{~Hz}$ & $13.04 \mathrm{~Hz}$ & $15.70 \mathrm{~Hz}$ \\
\hline & $12.03 \mathrm{~Hz}$ & 1 & 0.04911 & 0.08804 \\
\hline & $13.04 \mathrm{~Hz}$ & 0.04911 & 1 & 0.04874 \\
\hline & $15.70 \mathrm{~Hz}$ & 0.08804 & 0.04874 & 1 \\
\hline
\end{tabular}

Operasyonel modal analiz çalışması öncesinde SAP2000 yazılımı kullanılarak hazırlanan sonlu elemanlar modeli üzerinde hesaplanan teorik modal analiz sonuçları ile deneysel çalışma sonucunda yap1 üzerinde elde edilen modal davranış parametreleri Tablo 3' te karşılaştırmalı olarak sunulmuştur. Değerlendirme neticesinde; deneysel ve teorik mod şekillerinin aynı olduğu belirlenmiştir. Bununla birlikte, modal frekanslar kiyaslandığında $\sim \% 75-100 \quad$ mertebesinde, oldukça büyük, farklar olduğu tespit edilmiştir. Çalışma başlangıcında oluşturulan sonlu elemanlar modelinde dolgu duvarların ağırlıkları modele yansıtılmış; ancak yanal rijitliğe olan katkıları ihmal edilmiştir. Teorik ve deneysel modal frekanslar arasındaki farkın dolgu duvar etkisinden kaynaklanabileceğine işaret eden Okuyucu [34] benzeri çalışmalar dikkate alınarak; sonlu elemanlar modelinin deneysel modal analiz sonuçlarına yakın sonuçlar verecek şekilde kalibre edilmesi gerektiği sonucuna ulaşılmıştır. Buradaki temel amaç, sonlu elemanlar modeli üzerinde daha sonra gerçekleştirilecek yapısal analizlerde (performans belirleme, artımsal itme analizleri, $v b$.) kullanılacak, dinamik davranış parametreleri üzerinden kalibre edilmiş bir modelin oluşturulmasıdır.

Tablo 3. Teorik ve deneysel modal davranış parametrelerinin karşılaştırılması

Table 3. Comparison of theoretical and experimental modal analysis results

\begin{tabular}{ccccc}
\hline \multirow{2}{*}{ Mod } & \multirow{2}{*}{ Mod Şekli } & \multicolumn{2}{c}{ Modal Frekans (Hz) } & \multirow{2}{*}{ Fark (\%) } \\
\cline { 3 - 4 } & X Yönünde Yatay Öteleme & Teorik (dolgu duvarsız) & Deneysel & 76.92 \\
\hline 1 & Y Yönünde Yatay Öteleme & 6.801 & 12.032 & 75.45 \\
\hline 2 & Z Ekseni Etrafinda Burulma & 7.431 & 13.038 & 98.26 \\
\hline 3 & & 7.917 & 15.696 & \\
\hline
\end{tabular}

Sonlu elemanlar model kalibrasyonu çalışmalarında genel olarak; Costa vd. [35] çalışmasında da belirtildiği şekilde mesnet koşullarının güncellenmesi, geometrik ölçülerin gözden geçirilmesi ya da malzeme özelliklerinin değiştirilerek analizlerin yenilenmesi yöntemleri kullanılmaktadır. Bu çalışmada, deneysel ve teorik mod şekilleri gerek sıralama ve gerekse şekil olarak aynı çıktığından mesnet koşulları ve geometrik ölçülerin güncellenmesi yöntemlerinin kullanılmasına gerek duyulmamıştır. Malzeme elastik modül değerlerinin değiştirilmesi suretiyle, deneysel modal analiz sonuçları elde edilmeye çalışılmıştır. Başlangıçta oluşturulan sonlu eleman modelinde; TS500 [36] uyarınca C20 sınıfi beton için elastik modül değeri $28534 \mathrm{MPa}$ olarak hesaplanmıș ve tüm taşıyıcı elemanlara bu 
değer atanmıştır. Modal frekans farkını azaltmak için söz konusu elastik modül değeri artırılarak analizler tekrarlansa da deneysel sonuçlara yakın değerler elde edilmesi mümkün olmamıştır. Bu durumda; dolgu duvarların diyagonal çaprazlar şeklinde modele eklenmesi yoluna gidilmiştir. Dolgu duvarların betonarme çerçeve türü yapıların davranışı üzerindeki etkisinin deneysel ve teorik olarak incelendiği çok sayıda çalışmaya literatürde erişim sağlamak mümkündür. $\mathrm{Bu}$ çalışmalar arasında; Polyakov [37] çalışması dolgu duvarların çerçeve davranışı üzerindeki etkisinin incelendiği en eski çalışmalardan birisi olarak bilinmektedir. Mainstone [38] ise kendinden önceki önemli çalışmaları temel alarak; dolgu duvarların yapısal modellemede eşdeğer diyagonal çapraz elemanlar ile temsil edilmesine ilişkin formülasyon önerisini geliştirmiştir. $\mathrm{Bu}$ çalışmalardan hareketle, kalınlıkları $\sim 250 \mathrm{~mm}$ olan duvar kalınlığına eşit; genişlikleri ise $500 \mathrm{~mm}$ olan kesitlere sahip diyagonal basınç çubukları olarak sonlu elemanlar modeline eklenmiştir. Sadece eksenel basınca çalışan diyagonal elemanlar çerçevelere moment aktarmayan birleşimler şeklinde bağlanmıştır. Tablo 4' te sunulan çapraz eleman elastik modül değerleri belirlenirken duvarların boşluk oranları ve TBDY-2018 [39]' de sunulan duvar elastik modül bağıntısı dikkate alınmıştır.

Tablo 4. Duvarları temsil eden diyagonal çubuk elemanlar için belirlenen elastik modül değerleri Table 4. Modulus of elasticity values for diagonal struts that represent infill walls

\begin{tabular}{cc}
\hline Eleman & Elastik Modül (MPa) \\
\hline Kolon, kiriş ve döşeme & 28534 \\
\hline İç duvar diyagonal eleman & 3000 \\
\hline Batı duvar diyagonal eleman & 3150 \\
\hline Doğu duvar diyagonal eleman & 5450 \\
\hline Güney duvar diyagonal eleman & 2900 \\
\hline Kuzey duvar diyagonal eleman & 3720 \\
\hline
\end{tabular}

Dolgu duvar eklentileri ile kalibre edilmiş model üzerinden hesaplanan teorik modal analiz sonuçları ile deneysel modal analiz sonuçları Tablo 5' te karşılaştırılmıştır. Mod şekillerinin aynı ve ilgili modal frekanslar arasındaki farkın $\sim \% 1$ değerinin altında olduğu görülmüştür. $\mathrm{Bu}$ sonuç, yapısal eleman olarak kabul edilmeyen dolgu duvarların betonarme taşıyıcı sistem yanal rijitliğini önemli ölçüde artırdığını göstermektedir.

Tablo 5. Kalibre edilmiş sonlu elemanlar modeli üzerinde hesaplanan teorik ve deneysel modal davranış parametrelerinin karşılaştırılması

Table 5. Comparison of experimental and theoretical modal behavior parameters that calculated on calibrated finite element model

\begin{tabular}{ccccc}
\hline \multirow{2}{*}{ Mod } & \multirow{2}{*}{ Mod Şekli } & \multicolumn{2}{c}{ Modal Frekans (Hz) } & \multirow{2}{*}{ Fark $(\%)$} \\
\cline { 3 - 5 } & X Yönünde Yatay Öteleme & Kalibre Edilmiş Teorik & Deneysel & 0.01 \\
\hline 1 & Y Yönünde Yatay Öteleme & 12.031 & 12.032 & -0.02 \\
\hline 2 & Z Ekseni Etrafında Burulma & 13.041 & 13.038 & -0.30 \\
\hline 3 & & 15.743 & 15.696 & \\
\hline
\end{tabular}

Çalışmanın bütününde teorik ve deneysel olarak belirlenen modal davranış parametreleri toplu halde Tablo 6'da sunulmaktadir. Tablo incelendiğinde duvarların ihmal edildiği sonlu elemanlar modeli üzerinden hesaplanan modal frekans değerlerinin; mevcut yapı üzerinde operasyonel modal analiz yöntemi ile belirlenen değerlerin yaklaşık yarısı mertebesinde olduğu görülmektedir. Dolgu duvarların diyagonal çaprazlar olarak modele eklenmesi ile birlikte deneysel olarak elde edilen modal davranış parametreleri yakalanmıştır. $\mathrm{Bu}$ durum, dolgu 
duvarların betonarme çerçeve türü sistemlerde yap1 yanal rijitliğini önemli ölçüde etkilediğini, Smith [40], Okuyucu [34] ve Baran [41] çalışmalarına benzer şekilde, bir kez daha ortaya koymuştur.

Tablo 6. Yapı için belirlenen teorik ve deneysel modal analiz sonuçları

Table 6. Theoretical and experimental modal analysis results of the structure

\begin{tabular}{ccccc}
\hline \multirow{2}{*}{ Mod } & Mod Şekli & \multicolumn{2}{c}{ Modal Frekans (Hz) } \\
\cline { 3 - 5 } & & $\begin{array}{c}\text { Duvar } \\
\text { Eklentisiz } \\
\text { Teorik Model }\end{array}$ & $\begin{array}{c}\text { Operasyonel Modal } \\
\text { Analiz }\end{array}$ & $\begin{array}{c}\text { Duvar Eklentili-Kalibre } \\
\text { Teorik Model }\end{array}$ \\
\hline 1 & X Yönünde Yatay Öteleme & 6.801 & 12.032 & 12.031 \\
\hline 2 & Y Yönünde Yatay Öteleme & 7.431 & 13.038 & 13.041 \\
\hline 3 & Z Ekseni Etrafında Burulma & 7.917 & 15.696 & 15.743 \\
\hline
\end{tabular}

\section{Sonuçlar}

$\mathrm{Bu}$ çalışmada; hakkında hiçbir teknik bilgi bulunmayan, tek katlı betonarme bir yap1 ele alınmış ve operasyonel modal analiz yöntemi kullanılarak modal davranışı incelenmiştir. Çalışmanın malzeme karakterizasyonundan oluşan ilk safhasından itibaren tahribatsız yöntemler kullanılmıştır. Operasyonel modal analiz çalışması ile dinamik davranış parametrelerinin belirlenmesi ve bu sonuçlar kullanılarak sonlu elemanlar modelinin kalibre edilmesi mümkün olmuştur. Elde edilen nihai modelin, sonraki safhalarda gerçekleştirilecek yapısal analizlere esas model olarak kullanılabileceği sonucuna ulaşılmıştır. Çalışma neticesinde aşağıdaki değrlendirmelerin yapılması mümkündür:

- Betonarme taşıyıcı elemanların imal edildiği beton malzeme karakterizasyonu için Schmidt çekici ve ultrases yöntemi uygulamaları gerçekleştirilmiş; ancak ultrases yöntemi uygulamasından tutarlı sonuçlar elde edilememiştir.

- $\mathrm{Bu}$ çalışmanın en tartışmalı yanı; basınç mukavemeti testi ile belirlenmiş bir beton dayanımının bilinmeyişi ve Schmidt çekici uygulaması ile elde edilen değerlerin analizlerde kullanılmış olmasıdır. Binadan karot numune alımı yapılmamıştır.

- Operasyonel modal analiz uygulaması için yapı üzerinde toplam sekiz set titreşim ölçümü alınmış, tamamı üzerinden veri işleme çalışması yapılmıştır. Bu ölçümlerden, yap1 çevresinde akan trafiğin en yoğun olduğu saatte alınan ölçüm üzerinde yapılan veri işleme çalışmasında; ilk iki mod şekli otomatik olarak elde edilmiştir. Bu nedenle incelenen yap1 ve benzeri yapılar için çevresel titreşim etkilerinin yoğun olduğu zamanlarda yap1 tepkilerinin ölçülmek suretiyle operasyonel modal analiz uygulaması yapılması önerilmektedir.

- Dolgu duvarların yapı yanal rijitliğine olan katkısının ihmal edildiği sonlu elemanlar modeli üzerinde hesaplanan teorik modal analiz sonuçları ile operasyonel modal analiz çalışması ile elde edilen modal davranış parametleri karşılaştırıldığında; ilk üç mod şeklinin uyumlu olduğu, ancak modal frekanslar arasında farklar oluştuğu belirlenmiştir.

- Sonlu elemanlar modelinin güncellenerek operasyonel modal analiz sonuçlarına yakın modal davranış parametreleri elde edilebilmesi için öncelikle beton elastik modül değerinin artırılması yoluna gidilmiş; ancak bu çalışmadan olumlu sonuç alınamamıştır. Literatürde malzeme elastik modülünün değiştirilmesi suretiyle yapısal model kalibrasyonu gerçekleştirilen çok sayıda yığma yapı uygulamasına, Aslay (2019) örneğindeki gibi, erişim sağlamak mümkündür. Yığma yapılarda ana taşıyıcıların duvarlar olması ve duvar elastik modül değerinin değiştirilmesi ile tüm sistem rijitliğinin değiştirilerek model kalibrasyonu yapılmas1 mümkündür. Ancak, betonarme çerçeve türü yapılarda, yanal rijitlik sadece ana taşıyıcı elemanlara bağlı olmayıp çerçeve açıklıklarındaki dolgu duvarların katkısı da önemlidir. $\mathrm{Bu}$ nedenle, dolgu duvar 
rijitliklerinin ihmal edilip sadece beton malzeme özelliklerinin değiştirilmesi ile incelenen betonarme yaprya ait sonlu eleman modeli kalibrasyonunun yapılması mümkün olmamiştır.

- Model kalibrasyonu çalışmasının ikinci aşamasinda dolgu duvarlar sonlu elemanlar modeline salt eksenel basınca çalışan çapraz elemanlar olarak tanımlanmış; elastik modül değerleri belirlenirken ilgili duvar boşluk oranı hesaba katılmıştır. $\mathrm{Bu}$ şekilde oluşturulan sonlu elemanlar modeli üzerinde hesaplanan modal davranış parametrelerinin operasyonel modal analiz uygulaması ile yapı üzerinde elde edilen değerlere çok yakın olduğu (en büyük frekans farkı \%0.3) görülmüştür. Benzer çalışmalarda, dolgu duvarların ve duvar tanımlama aşamasında boşluk oranlarının dikkate alınması önerilmektedir.

- Betonarme çerçeve türü yapılar ülkemizdeki mevcut yap1 stoğunun çok önemli bir bölümünü oluşturmaktadır. Kentsel dönüşüm uygulamaları kapsamında bu yapıların performans değerlendirmelerinin yapılması ve yap1 hakkında teknik kararlar verilmesi nitelikli inşaat mühendisliği hizmeti alımını gerektirmektedir. $\mathrm{Bu}$ yapıların büyük bölümüne ilişkin mimari-statik proje, vb. teknik dokümana erişim sağlamanın mümkün olmadığı da bir gerçektir. Bu bakımdan, bu metinde detayları sunulan araştırmaya benzer çalışma sayısı ve uygulama bilgisi arttıkça; tahribatsı bir yöntem olan operasyonel modal analiz ile mevcut betonarme yapiların durum tespiti ve yapisal performans değerlendirmelerinin yap1 genelinden elde edilecek modal davranış parametreleri üzerinden yapılmasının önemli bir teknik kazanım olacağı düşünülmektedir. Betonarme çerçeve türü yapılar üzerinde operasyonel modal analiz uygulaması sayısının artırılarak çalışma detay ve sonuçlarının literatüre eklenmesine ihtiyaç olduğu ifade edilebilir.

\section{Teşekkür}

Yazar, sundukları katkılar ile çalışmayı mümkün kılan Erzurum Teknik Üniversitesi Yapı İşleri Daire Başkanı Sayın Ali ÇELIKK ve Güvenlik Birimi Amiri Sayın Murat UCUN' a destekleri için teşekkür eder.

\section{Kaynaklar}

[1] URL-1: https://insapedia.com/schmidt-cekicibeton-test-cekici-deneyi/ (Erişim tarihi: 07.01.2020)

[2] Kazemi, M., Madandoust, R., de Brito, J., (2019). Compressive strength assessment of recycled aggregate concrete using schmidt rebound hammer and core testing, Construction and Building Materials, 224, 630-638.

[3] Müller, P., Novák, J., Holan, J., (2019). Destructive and non-destructive experimental investigation of polypropylene fibre reinforced concrete subjected to high temperature, Journal of Building Engineering, 26: Article 100906.Z.

[4] Whitehurst, E.A., (1951). Use of the soni scope for measuring setting time of concrete, ASTM, 51, ,1166-1176.

[5] Durmuş, G., Yılmaz, C., (2009). Farklı oranlardaki yapay puzolan katkılı betonların su işleme derinliğinin ultrases geçiş hızı ile değerlendirilmesi, e-Journal of New World Sciences Academy, 4,1, Article Number: $1 \mathrm{~A} 0006$.

[6] Abdullah, V., Aydın, E., Bedirhanoğlu, İ., (2017). Beton elasatisite modülünün ultrasonik ses dalgası yayılma hızı ile tahmin edilmesi, Dicle Üniversitesi Mühendislik Fakültesi Dergisi, 8, 3, 475-484.

[7] Ahn, E., Shina, M., Popovicsb, J.S,, Weaverc, R.L., (2019). Effectiveness of diffuse ultrasound for evaluation of micro-cracking damage in concrete, Cement and Concrete Research, 124, Article Number 105862.

[8] URL-2: https://www.pcte.com.au/rebar-location (Erişim tarihi:06.02.2020)

[9] Rathod, H., Debeck, S., Gupta, R., Chow, B., (2019). Applicability of GPR and a rebar detector to obtain rebar information of existing concrete structures, case studies in construction materials, 11, e00240.

[10] Brincker, R., Ventura, C., (2015). Introduction to Operational Modal Analysis, West Sussex: John Wiley \& Sons Ltd, Press.

[11] Yetkin, M., (2016). Betonarme yapıların çevresel titreşim verileri kullanılarak dinamik davranışlarının incelenmesi, Yüksek Lisans Tezi, Fırat Üniversitesi, Elazığ.

[12] Link, M., (1993). Updating of analytical modelsprocedures and experience. Proc., Conference on Modern Practice in Stress and Vibration Analysis, Sheffield, UK, 35-52. 
[13] Altunışık, A.C., Karahasan, O.S., Genç, A.F., Okur, F.Y., Günaydın, M., Kalkan, E., Adanur, S., (2018). Modal parameter identification of RC frame under undamaged, damaged, repaired and strengthened conditions, Measurement, 124, 260-276.

[14] Polimeno, M.R., Roselli, I., Luprano, V.A.M., Mongelli, M., Tati, A., de Canio, G., (2018). A nondestructive testing methodology for damage assessment of reinforced concrete buildings after seismic events, Engineering Structures, 163, 122136.

[15] Şafak, E., Çelebi, M., (1992). Recorded seismic response of Pacific Park Plaza. II: system 1dentification, Journal of Structural Engineering, 118, 1566-89.

[16] Zhu, Y.C., Xie, Y.L., Au, S.K., (2018). Operational modal analysis of an eight-storey building with asynchronous data incorporating multiple setup, Engineering Structures, 165, 50-62.

[17] Cantieni, R., (2005). Experimental methods used in system 1dentification of civil engineering structures. Proc., $1^{\text {st }}$ International Operational Modal Analysis Conference, Copenhagen, Denmark, 249-260.

[18] Bayraktar, A., Türker, T., Altunışık, A.C., Sevim, B., Özcan, M., (2010). Binaların dinamik parametrelerinin operasyonel modal analiz yöntemiyle belirlenmesi, IMO Teknik Dergi, 51855205.

[19] Brincker, R., Andersen, P., Zhang, 1., (2000). Modal identification from ambient responses using frequency domain decomposition. Proc., $18^{\text {th }}$ International Modal Analysis Conference (XVIII IMAC), San Antonio, Texas, USA.

[20] AUTOCAD, (2019). Design and Drafting Softvare, Erzurum Teknik Üniversitesi.

[21] SAP2000, (2019). Structural Softvare for Analysis and Design, Erzurum Teknik Üniversitesi.

[22] Saisi, A., Gentile, C., Guidobaldi, M., (2015). Postearthquake continuous dynamic monitoring of the Gabbia Tower in Mantua - Italy, Construction and Building Materials, 81, 101-112.

[23] Özkul M., (2016). Determination of structural safety of a historical structure using operational analysis, Yüksek Lisans Tezi, Ege Üniversitesi, İzmir.

[24] Kocaman, İ., Okuyucu, D., Kazaz, İ., (2019). Tarihi yapı malzeme özelliklerinin dinamik parametrelerle belirlenmesi: Lala Paşa Camii Örneği, İMO Teknik Dergi, 30, 3, 9146-9125.

[25] Aslay, S.E., Okuyucu, D., (2019). Erzincan Değirmenliköy Kilisesi apsis hasarının teknik olarak araştırılması, Gazi Üniversitesi Mühendislik Mimarlık Fakültesi Dergisi, 35, 1, 402-387.

[26] Türker, T., (2005). Çelik çerçeve sistemlerin dinamik karakteristiklerinin deneysel modal analiz yöntemiyle belirlenmesi, Yüksek Lisans Tezi, Karadeniz Teknik Üniversitesi, Trabzon.

[27] Kömür, M., Deneme, İ., Yerli, H., (2016). Düzlem çelik çerçeve sistemlerin operasyonel modal analizi, Çukurova Üniversitesi MühendislikMimarlık Fakültesi Dergisi, 30, 2, 80-73.

[28] TestLab Network, (2019). Dinamik Veri Toplama Yazılımı, Erzurum Teknik Üniversitesi.

[29] Jacobsen, N.J., Andersen, P., (2008). Operational modal analysis on structures with rotating parts. Proc., ISMA Conference: International Conference On Noise And Vibration Engineering, Leuven, Belgium.

[30] Artemis Modal Pro, (2019). Operational Modal Analysis Softvare, Erzurum Teknik Üniversitesi.

[31] Pastor, M., Binda, M., Harcarik, T., (2012). Modal assurance criterion, Procedia Engineering, 48, 543-548.

[32] URL-3:

http://www.svibs.com/resources/ARTeMIS_Modal_Help/Generic\%20M odal\%20Assurance\%20Criterion\%20Window.html (Erişim tarihi:06.02.2020)

[33] Zebari, Z., Bedirhanoğlu, İ., Aydın,E.,(2017). Beton basınç dayanımının ultrasonik ses dalgası yayılma hızı ile tahmin edilmesi, Dicle Üniversitesi Mühendislik Fakültesi Mühendislik Dergisi,8,1,5243.

[34] Okuyucu, D., (2011). Effects of frame aspect ratio on the seismic performance improvement of PC panel strengthening technique, Doktora Tezi, Ortadoğu Teknik Üniversitesi, Ankara.

[35] Costa, C., Ribeiro, D., Jorge, P., Arede, A., Calçada, R., (2016). Calibration of the numerical model of a stone masonry railway bridge based on experimentally 1dentified modal parameters, Engineering Structures, 123, 354-371.

[36] TS500-2000, Betonarme Yapıların Tasarım ve Yapım Kuralları, Türk Standartları Enstitüsü, Ankara, (2000).

[37] Polyakov, S.V., (1956). On the interaction between masonry filler walls and enclosing frame when loaded in the plane of the wall, translation in earthquake engineering, Earthquake Engineering Research Institute, San Francisco, USA, 36-42.

[38] Mainstone, R., (1971). On the stiffness and strength of infilled frames, Proceedings Instution of Civil Engineers, 48, 57-90.

[39] TBDY-2018, Türkiye Bina Deprem Yönetmeliği, Afet ve Acil Durum Yönetimi Başkanlığı, Ankara, (2018)

[40] Smith, B.S., (1962). Lateral stiffness of infilled frames, ASCE Journal of Structural Division, 88, 6 , 183-199.

[41] Baran, M., (2012). Dolgu duvarların betonarme çerçeveli yapılarınn davranışı üzerindeki etkilerinin incelenmesi, Gazi Üniversitesi Mühendislik Mimarlık Fakültesi Dergisi, 27, 2, 275-284. 